Original Research Paper

\title{
Flow Dynamic Behavior of Fish Oil/Silver Nitrate Solution in Mini-Channel, Effect of Alkane Addition on Flow Pattern and Interfacial Tension
}

\author{
Kirubanandan Shanmugam \\ Department of Process Engineering and Applied Science, \\ Dalhousie University, PO Box 15000 Halifax, Nova Scotia, Canada B3H 4R2, Canada
}

Article history

Received: 23-01-2016

Revised: 09-02-2016

Accepted: 24-02-2016

\begin{abstract}
The mini-fluidic contacting system is developed as process intensification platform as an attractive alternative for existing liquidliquid extraction system for separation of Omega 3 PUFA from using Aqueous 50\% Wt. Silver nitrate solution. To improve the performance of extraction in mini-fluidics, it is necessary to study the flow-dynamic behavior of fish oil silver nitrate system in the channel. Moreover, different flow patterns influence mass transfer and mixing which indirectly influence the separation efficiency of omega 3 PUFA from fish oil. Therefore, Different flow patterns were studied at Y-junction that connected to mini-channel and classified over a range of organic phase and aqueous flow rate. The flow is stratified at the "Y" Junction after phase inversion and also due to the reduction of interfacial tension between fish oil and silver nitrate solution. The addition of alkane's solvents into the fish oil ethyl ester is attempted to change the flow pattern of fish oil silver nitrate system by elevation of interfacial tension. The formation mechanism of slug and stratified flow was studied by a competition between the gravity, inertia, viscous forces and the interfacial tension forces. The flow patterns maps is presented in terms of $\mathrm{Ca}, \mathrm{Re}$ and We and identified the three regions namely gravity force dominant region, transition region and interfacial force dominant region. The flow patterns observed in real Fish Oil/ $\mathrm{AgNO}_{3}$ system was significantly different than previously reported for a synthetic $\mathrm{DHA} / \mathrm{AgNO}_{3}$ system. The addition of organic solvent into the fish oil ethyl ester increase the interfacial tension between fish oil and silver nitrate system, however, the increase was not sufficient to produce slug flow. This would suggest that practical processing of fish oils with $\mathrm{AgNO}_{3}$ would require the handling of stratified flow within the processing units.
\end{abstract}

Keywords: Mini-Channel, Liquid-Liquid Flow, Stratified Flow, Slug Flow and Interfacial Tension

\section{Introduction}

Previously, the mini-fluidic reactor technology has been developed for silver based solvent extraction of Omega 3 PUFA from fish oil esters. However, the stratification of flow is observed instead of Slug flow pattern.

In order to improve the performance of slug flow mini-fluidic reactor technology, it is necessary to investigate flow patterns of the fluids at mini-scales and various dominating forces to control the flow patterns.
Hydrodynamics is the key role in controlling the mass transfer and kinetics in any type of chemical reaction. In mini-fluidic channels, specific flow patterns are observed for two immiscible fluids, including stratified flow, wavy annular flow and slug/plug flow. Usually the flow patterns at mini/micro scales are well-defined and thus the interfacial areas of the flows are uniform, allowing simple and precise modeling of numerous chemical processes. Among the various flow patterns, slug flow offers promising advantages in mini/micro- 
fluidic liquid-liquid extraction because of the large interfacial area-to-volume ratio and an increased mass transfer coefficient due to liquid recirculation within each slug (Kamio et al., 2011). This enhances the rate of extraction in the mini-fluidic contacting system and microfluidics system.

As mini-fluidic contacting system has the dimension in the range of $0.5 \mathrm{~mm}<\mathrm{ID}<3 \mathrm{~mm}$, interfacial tension and viscous forces dominate the effects of gravity and inertia forces. Three dimensionless numbers, the Weber, Capillary and Bond numbers, are significant in characterizing multiphase phenomena in such mini scale flows. The Bond number is often used to justify whether flow is dominated by interfacial tension force or gravity force, thereby defining the point at which geometry is "mini" or "micro" scale. However, it strongly depends on the nature of binary liquid systems, but it affects the formation of flow patterns in the mini-channel. There are two types of liquid-liquid two phase flows that can result when working with liquids at the micro- and mini-fluidic scales: Slug flow and parallel flow. The capillary number can be used to predict the presence of such flow. A capillary number less than 1 indicates that the forces of interfacial tension dominate viscous forces, resulting in a decrease in the interfacial area. Depending on device geometry, a decrease in interfacial area could lead to slug flow or parallel flow. A capillary number greater than 1 often results in parallel flow due to the viscous fluid's resistance to shear which extends the interface down the length of the channel. At low Bond numbers this results in the eventual formation of slug flow, while at high Bond numbers stratified flow can result. The Weber number is used to predict when inertial forces become so significant that they lead to instabilities at the interface of two phase flow, which can also contribute to a transition from slug to stratified flow. A Weber number greater than 1 is indicative of flow instabilities. These dimensionless numbers are used to analyse the flow patterns of fish oil ethyl ester and silver nitrate systems at mini scale dimension. The Table 1 describes about dimensionless numbers used in the multiphase flow at mini/micro scale and these numbers used to characterize the dominating force which does influence flow patterns in mini-channels.

The reported literature on extraction of Omega 3 PUFA in mini-fluidic contacting system has been attempted with extraction of only DHA dissolved in nHeptane solvents with silver nitrate solution, typically with slug flow or emulsion flow patterns present (Table 2 ). In contrast, a practical evaluation of extraction performance using commercial 18/12EE fish oils yielded completely different flow behavior than the idealized systems. Stratified flow is quite rare within these systems due to the increased dominance of surface forces at these scales, which tends to result in the formation of slug flow. In the case of slug flow, two mechanisms are known to be responsible for the mass transfer between two immiscible liquids: Internal circulation within each slug and the concentration gradients between adjacent. In the case of stratified flow, the flow is laminar and the transfer of molecules between the two phases is supposed to occur only by diffusion (Vir et al., 2014). We would thus expect a lower performance in a stratified flow system than that observed within a slug-flow system.

Limited reports are available of extraction performance using silver salts to isolate polyunsaturated fatty acids from a mixture of FFA, with previously known methods not providing for a sufficiently selective or efficient process for concentrating Omega-3 fatty acids. Breivik et al. (2012) reported that silver salt solutions could be used in the extraction of PUFA from marine oils, describing a potential process which is summarized as follows. Table 2 describes the flow patterns involved in extraction of Omega 3 PUFA with silver nitrate solutions in mini-channel.

Table 1. Dimensionless number used in fluid flow

\begin{tabular}{llll}
\hline Dimensionless numbers & Definition & Formulae & Implications \\
\hline Reynolds number & $\frac{\text { Inertia force }}{\text { Viscous force }}$ & $\mathrm{Re}=\frac{d_{H} \rho u}{\mu}$ & $\mathrm{Re}<2100$ - Laminar flow \\
Weber number & $\frac{\text { Inertia force }}{\text { Interfacial tension force }}$ & $\mathrm{We}=\frac{d_{H} \rho u^{2}}{\sigma}$ & $\mathrm{Re}>2300$ - Turbulent flow \\
Capillary number & $\frac{\text { Viscous Force }}{\text { Intenfacial tenstion force }} \rightarrow$ stable interface \\
& $\frac{\text { Gravity Force }}{\text { Bntenfacial tenstion }}$ & $\mathrm{Ca}=\frac{\mu u}{\sigma}$ & $\mathrm{Ca}<1$ - reduce interfacial area \\
& $\mathrm{Bo}=\frac{\Delta \rho g d^{2}{ }_{H}}{\sigma}$ & $\mathrm{Ca}>1 \rightarrow$ parallel flow \\
& & $\mathrm{Bo}>1$, Gravity Force dominates \\
\hline
\end{tabular}




\begin{tabular}{|c|c|c|c|c|}
\hline Organic phase & Aqueous phase & $\begin{array}{l}\text { Mini-channel configuration } \\
\text { and diameter }\end{array}$ & Flow pattern & Reference \\
\hline DHA Et & $\mathrm{AgNO}_{3}$ & $\begin{array}{l}0.005 \mathrm{~m} \text { Connected } \\
\text { "Y" Junction to mix the Organic } \\
\text { and Aqueous Phase }\end{array}$ & Slug Flow & Kamio et al. (2010) \\
\hline DHA Et & $\mathrm{AgNO}_{3}$ & $\begin{array}{l}0.005 \text { m Connected } \\
\text { "Y" Junction to mix the Organic } \\
\text { and Aqueous Phase }\end{array}$ & Slug Flow & Kamio et al. (2011) \\
\hline DHA Et & $\mathrm{AgNO}_{3}$ & $\begin{array}{l}\text { "Y" Shaped } \\
\text { Micro channel }\end{array}$ & $\begin{array}{l}\text { W/O Emulsion } \\
\text { Based drop flow }\end{array}$ & Kamio et al. (2011) \\
\hline $\begin{array}{l}\text { EPA Et } \\
\text { DHA Et }\end{array}$ & $\mathrm{AgNO}_{3}$ & $\begin{array}{l}\text { "T" Shaped } \\
\text { Micro reactor }\end{array}$ & Slug Flow & Seike et al. (2007) \\
\hline $\begin{array}{l}\text { Fish Oil } \\
\text { Ethyl Ester }\end{array}$ & $\mathrm{AgNO}_{3}$ & $\begin{array}{l}1.58 \mathrm{~mm} \text { Tygon mini-channel } \\
\text { connected to "Y" } \\
\text { Mixing section }\end{array}$ & Stratified Flow & $\begin{array}{l}\text { Donaldson (2013) } \\
\text { Shanmugam and } \\
\text { Donaldson (2015) }\end{array}$ \\
\hline
\end{tabular}

The objective of the present investigation has to be determined the influence of liquid-liquid flow patterns in $\mathrm{Y}$ shaped mixing section in Tygon and PFA mini-channel and to evaluate dominating force to control the flow patterns. To improve the performance of mini-fluidics, it is necessary to study the hydrodynamic behavior of fish oil silver nitrate system in the channel, identifying the reason for the shift in flow behavior observed and the impact this would have on mass transfer performance. The addition of non-polar organic solvents into the fish oil ethyl ester was attempted to change the flow pattern of fish oil silver nitrate system by elevation of interfacial tension. Flow pattern maps are presented in terms of $\mathrm{Ca}$, $\mathrm{Re}$ and We, with three regions of interest identified within the context of this specific system.

\section{Materials and Methods}

\section{Evaluation of Density of Silver Nitrate Solution and Fish Oil Ethyl Ester}

ASTM D1480 set forth the procedure to estimate the density and specific gravity of liquids using a Bingham Pycnometer. The technique is limited to liquids with vapor pressure less than $600 \mathrm{mmHg}$ and viscosity less than $40000 \mathrm{CSt}\left(\mathrm{mm}^{2} / \mathrm{s}\right)$ and specifically designed to conduct experiments at any temperature between 20 and $100^{\circ} \mathrm{C}$. This procedure allows measuring density at high temperatures on the compromise of the precision (ASTM Standard 1480, 2012). A pycnometer is a simple glass vessel with a long glass stopper consisting of a capillary hole to accommodat a fixed volume. The density is measured by weighing the sample filled pycnometer. The capillary determines the exact volume consequences the high resolution of density measurement. Initially, the empty vessel is weighed, followed by the weighing of distilled water filled vessel to measure the volume of the vessel. Finally the pycnometer is filled with sample liquid whose density is to be determined and weighted with high precision weighing machine. The density is estimated as the ratio of the mass of the sample liquid and volume of the liquid. The specific gravities of Silver nitrate solution, fish oil ethyl ester, 10\% Hexane 90 Fish Oil Ethyl ester, $50 \%$ Hexane $50 \%$ Fish Oil ethyl ester, 10\% Hexene 90 Fish Oil Ethyl ester, 50\% Hexene 50\% Fish Oil ethyl ester are evaluated using the density obtained.

In order to verify the experimental value of density, the value is predicted by various correlations. The specific gravity of the samples was determined using the specific gravity bottle method. Two bottles were used for each test simultaneously and repeated twice. The mass of the bottles and fuels were determined using a Mettler 110 Analytical balance. This test was performed according to ASTM D5355-95. The Density correlation between fish oil ethyl ester has been reported and the correlation was valid over the temperature range of $20-300^{\circ} \mathrm{C}$ Equation 1:

$\rho=-1.24 T+862.69$

The Andrade Equation for Kinematic and Dynamic viscosity correlation for fish oil ethyl ester has been reported and the correlation was valid in the temperature range of $10-300^{\circ} \mathrm{C}$ Equation 2 :

$\ln (v)=-0.453-\frac{739}{T}+\frac{415,238}{T^{2}}$

The physical properties of $50 \%$ Wt. silver nitrate solutions are calculated based on various literatures. The final density measured at experimental conditions was $1751 \mathrm{Kg} / \mathrm{m}^{3}$. The Viscosity of $50 \mathrm{wt} . \%$ concentrate silver nitrate solution is $0.0015 \mathrm{Kg} / \mathrm{m} . \mathrm{sec}$. Similarly, the density and viscosity of fish oil ethyl esters are 898 $\mathrm{Kg} / \mathrm{m}^{3}$ and $0.005732 \mathrm{Kg} / \mathrm{m} . \mathrm{sec}$.

The IFT of experimental fluids is evaluated by spinning drop tensiometry and reported the values in the chapter 3. However, in this section, the plot for IFT is reported at highest value of RPM. 


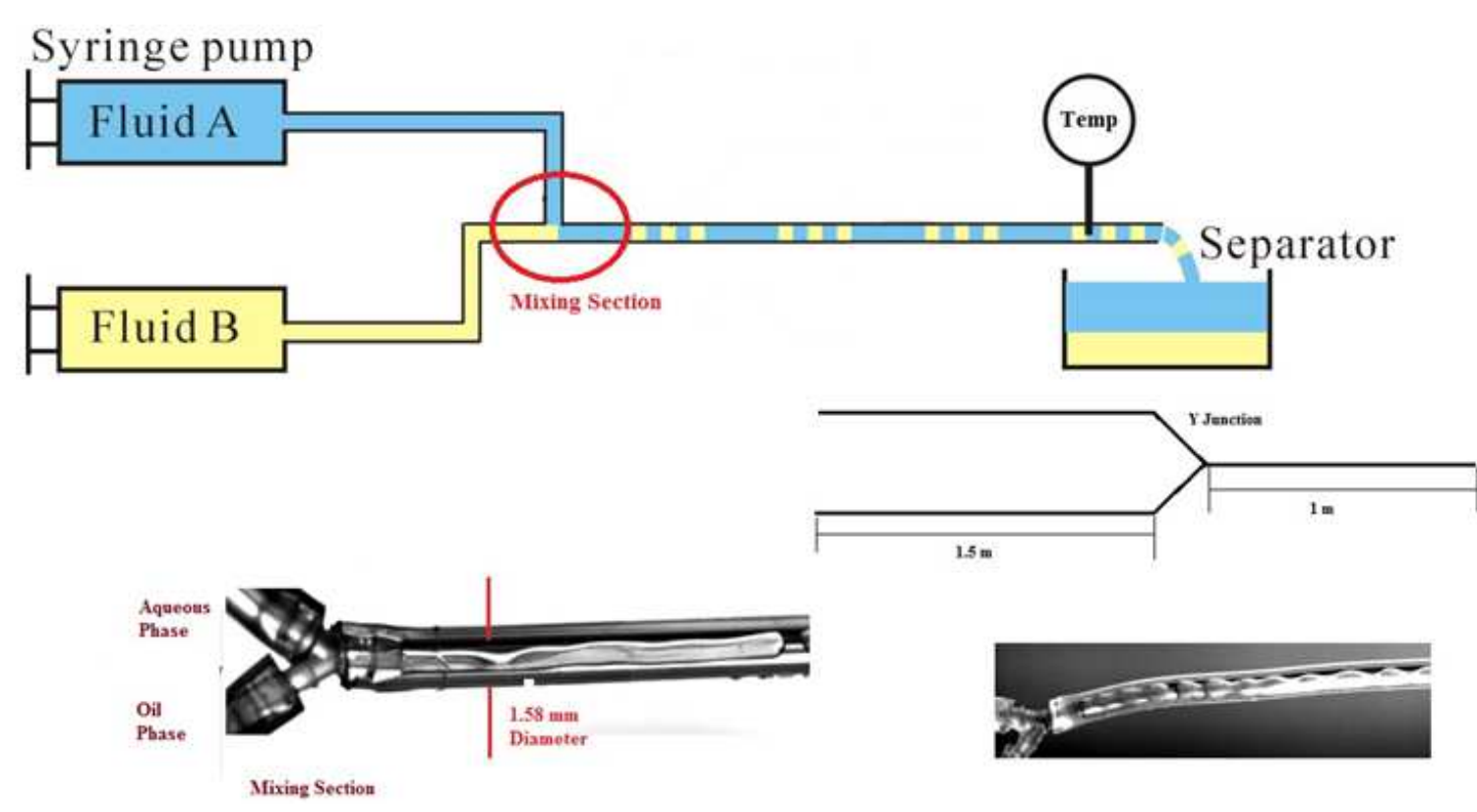

Fig. 1. Experimental set up and mixing section. The flow patterns at "Y" the mixing section have been captured by high speed camera

\section{Experimental System for Flow Visualization Studies}

A schematic of the experimental setup is shown in Fig. 1. In the experimental set up, each phase was pumped through a $1.5 \mathrm{~m}$ length of tubing submersed in a temperature controlled reservoir at $10^{\circ} \mathrm{C}$ to pre-cool the solution, after which time the phases were contacted in a Y-junction. Then Y-junction acts mixing section between two immiscible phases and the outlet of $\mathrm{Y}$ junction is connected to a mini-channel which comprises of a length of $1 \mathrm{~m}$ and inside diameter $1 / 16^{\text {th }}$ inch. Tygon material and PFA mini-channel have been selected as the material for flow patterns investigations. The flow patterns for different combinations of flow velocities (rates) are observed visually and photographed by a high speed camera (PCO Dimax). The high speed video camera was set to capture images of process fluids flow at a frame rate of up to 650 frames per second.

The flow regimes noticed during experimentation covers the aqueous phase dispersed and organic continuous phase patterns as well as the zone of transition between them.

\section{Results and Discussion}

\section{Flow Pattern Analysis}

\section{Properties of Experimental Fluid}

The physical properties of the experimental fluids are tabulated in Table 3. It is used in the evaluation of dimensionless numbers for flow patterns analysis and construction of flow patterns map for fish oil silver nitrate system.

\section{Flow Pattern Observed in Liquid-Liquid Extraction of Omega 3 PUFA from Fish Oil Ethyl Ester}

The various kinds flow patterns in mini channel was observed and tabulated in the Fig. 2 and 3. One notable difference between this study and previous mini-fluidic studies was the presence of a stratified flow patterns in the channels, where a slug flow profile was anticipated. In an attempt to quantify the degree to which the surface tension is modified by the addition of hexane and hexene solvents, surface tension measurements were performed by spinning drop tensiometry. When two immiscible liquids are pumped into the $\mathrm{Y}$-junction, the downstream section of Y-junction is connected to the mini-channel. The $\mathrm{Y}$-junction acts as mixing section of organic phase and aqueous phase and the various flow patterns were observed in the flow of two immiscible liquids in mini-channel at various flow rates especially in fish oil water system whereas fish oil silver nitrate system offers stratified flow at various flow rates. The Fig. 2 and 3 are shown various flow patterns observed in $1 / 16^{\text {th }}$ Inch ID of Tygon and PFA mini-channel for various systems.

Different flow patterns have been observed when organic phase and aqueous phase mixing together in Y-junction and flowing in the mini-channel. In this study, it is noted that the mini-channel was wetted with fish oil in Tygon channel and PFA channel. Moreover, interfacial tension between organic phase and aqueous phase plays an major role in controlling the flow pattern in mini-channel. However, due to 
drastic difference in density between fish oil and silver nitrate solution, startified flow pattern were oberved. The Fig. 2 and 3 shows how the flow rate of organic phase and aqueous phase flowed in different patterns in mini-channel. In contrast with fish oil water system and hexane/silver nitrate system, fish oil/silver nitrate system, $10 \mathrm{Hex} 90 \mathrm{FO}$ silver nitrate solution and 50 Hex 50 FO silver nitrate solution, stratifed flow pattern in Tygon and PFA min-channel were oberved even at low flow rates.

Figure 2 and 3 are shown the different flow patterns observed in minifludic contact system. Droplet, plug and slug flow, annular, wavy annular flow and stratified flow have been observed. In this study, the organic phase plug and slug were distingused according to their length, if the average length of the organic pahse segements was equal to or less than 5 channel diameters $(1.25 \mathrm{~mm}$ long), then the flow was classified as a plug flow. If the length of the organic phase segment greater than 5 channel diameter, the flow was classified as slug flow. As mentioned earlier, for each experimental fluid, the flow rate of both phase is varied. It is observed that stratifed flow pattern exists at flow rate of $10 \mathrm{ml} / \mathrm{min}$ and even in lower flow rate in the case of fish oil silver nitrate system.

Table 3. Properties of Experimental fluids at $15^{\circ} \mathrm{C}$

\begin{tabular}{lccc}
\hline Experimental Fluids & $\rho \mathrm{Kg} / \mathrm{m}^{3}$ & $\mu \mathrm{Kg} / \mathrm{m} . \mathrm{sec}$ & $\sigma \mathrm{mN} / \mathrm{m}$ \\
\hline Fish Oil EE & 898.8 & 0.00570 & 17.50 \\
Silver Nitrate Solution & 1751.4 & 0.00150 & 77.40 \\
Water & 999.7 & 0.00130 & 74.20 \\
Hexane & 695.0 & 0.00036 & 20.40 \\
Hexene & 673.0 & 0.00020 & 20.50 \\
$10 \%$ Hexane 90\% Fish Oil EE & 872.4 & 0.00510 & \\
$50 \%$ Hexane 50\% Fish Oil EE & 811.2 & 0.00300 & 2.50 \\
Fish Oil Water & 969.4 & 0.00290 & 0.34 \\
Fish Oil Silver Nitrate & & 0.00270 & 0.34 \\
10\% Hexane 90\% Fish Oil-Silver Nitrate & 808.0 & 0.00300 & 0.65 \\
50\% Hexane 50\% Fish Oil Silver Nitrate & 869.0 & 0.00240 & 560.00 \\
Hexane-Silver Nitrate & 1030.0 & 0.00160 & \\
\hline
\end{tabular}

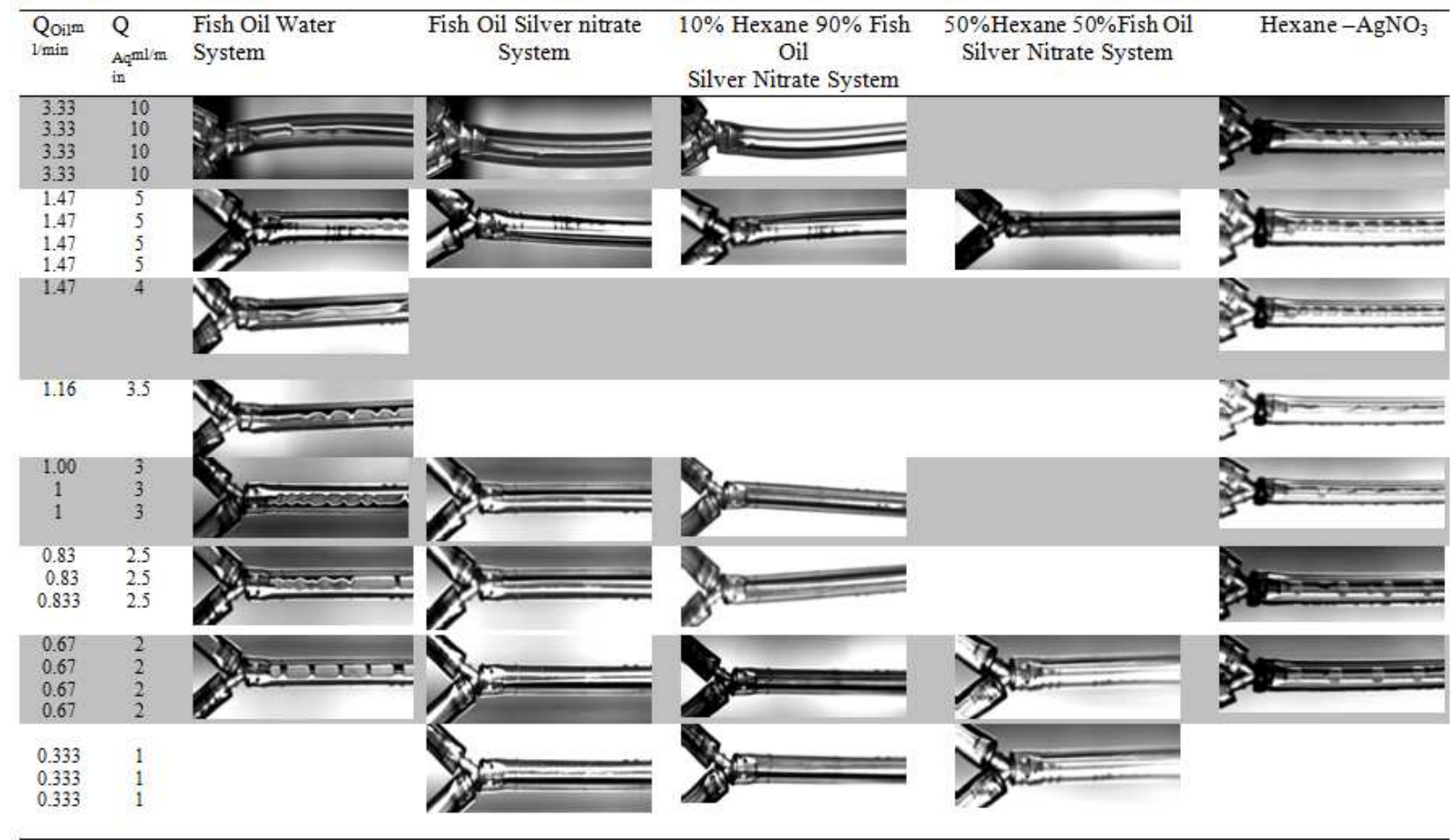

Fig. 2. Flow patterns Observed in 1/16th ID of Food Grade Tygon mini-channel. Oil Phase enters from bottom at various flow rate and Silver nitrate enters from top in ' $Y$ ' mixing junction at various flow rates 


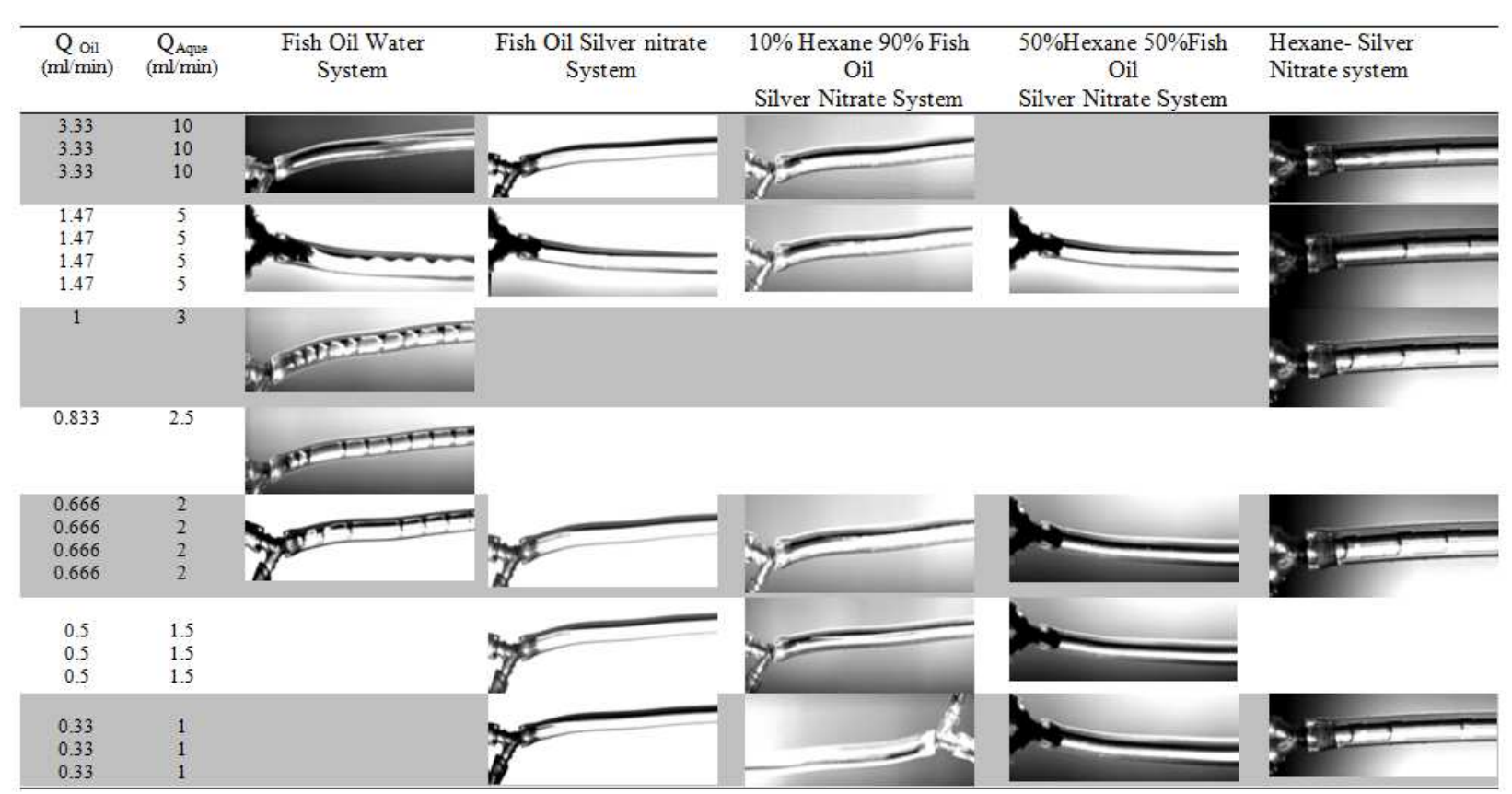

Fig. 3. Flow patterns observed in 1/16th ID of PFA mini-channel. Oil Phase enters from bottom at various flow rate and Silver nitrate enters from top in ' $Y$ ' junction at various flow rates. In Fish Oil Water system, Stratified, Wavy annular and plug, slug flow patter were observed. The stratified flow patter only observed in Fish Oil Silver nitrate system, 10 Hexane 90 Fish Oil-Silver nitrate system, 50 Hex 50 Fish Oil Silver Nitrate system. But In Hexane Silver nitrate system, Slug flow pattern was observed at $5 \mathrm{ml} / \mathrm{min}$ flow rate of silver nitrate and $1.47 \mathrm{ml} / \mathrm{min}$ of Hexane

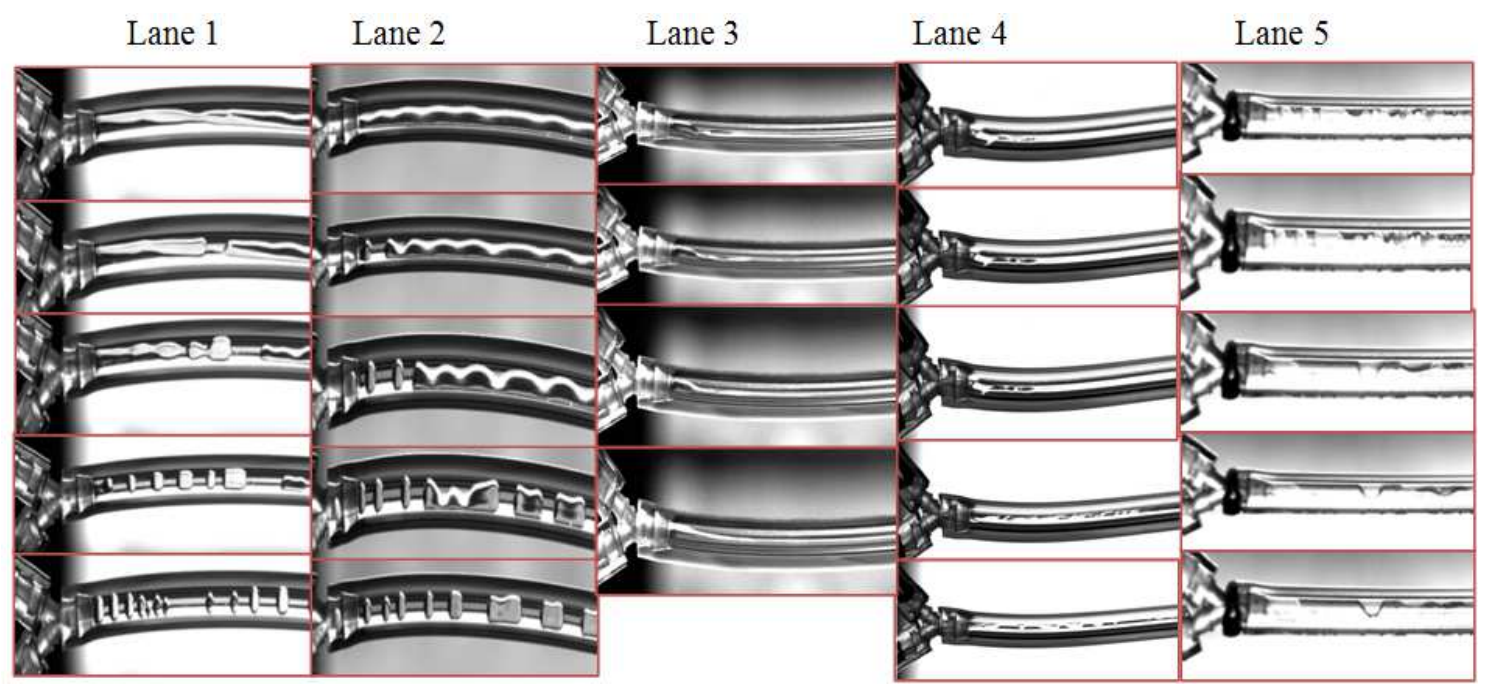

Fig. 4. Destabilization of Stratified flow after pump is stopped. Oil Phase on Bottom in the "Y" Junction and the aqueous phase in top in "Y" Junction and the destabilization of stratified flow that are observed in a 1/16th Inch of internal diameter Tygon mini-channel. The organic phase enters from bottom at $3.33 \mathrm{ml} / \mathrm{min}$ and aqueous phase enters from top at $10 \mathrm{ml} / \mathrm{min}$; Lane 1: Fish Oil/Water system (FO on Bottom in Y junction); Lane 2: Fish Oil Water System; Lane 3: Fish Oil/Silver Nitrate System; Lane 4: 10\% Hexane 90 FO Silver nitrate system; Lane 5: Hexane/Silver Nitrate System

In contrast with fish oil-water system and hexanesilver nitrate system, the flow was stratified at higher flow rate. However, with decrease in flow rate of both phase, a flow transition is followed from stratified flow to wavy anunular flow and then transition to slug flow at $3.5 \mathrm{ml} / \mathrm{min}$ of water and $1 \mathrm{ml} / \mathrm{min}$ of fish oil in fish oil water system and $5 \mathrm{ml} / \mathrm{min}$ of silver nitrate and 1.47 $\mathrm{ml} / \mathrm{min}$ in the case of hexane/silver nitrate system. 
However, the stratified flow were formed in fish oil/silver nitrate system, 10 Hex 90 fish oil silver nitrate system and 50 Hex 50 fish oil silver nitrate system.

\section{Destabilization of Stratified Flow}

At the flow rate of $3.33 \mathrm{ml} / \mathrm{min}$ of fish oil ethyl ester and $10 \mathrm{~mL}$ min of Water, stratification is observed once flow rate is constant and stabilized (Fig. 4 and 5). When the syringe pump is off, the stratified flow starts to destabilize and decrease in velocity of fish oil and water.

\section{Phase Inversion Phenomena}

The flow of two immiscible liquid (Fish Oil Water System, Fish Oil Silver Nitrate System and 10\% Hexane 90\% Fish Oil Silver Nitrate System) into the Y-junction and mixing together in the mini-channel exhibits the phenomenon of phase inversion in which dispersed phase inverts to form continues phase and vice versa with slight changes in the operating conditions (Fig. 6 and 7).

\section{Analysis of Flow Patterns based on Bond Number}

In the point of process intensification, reduing the dimensions of the channel geometry has an great impact on dominating forces on the fluid flow. In general, the interfacial forces play the most dominant forces especially in two immisible phase flow in minichannel. To compare the gravity, viscous and intertia forces with interfacial forces, dimensionless numbers will be used. However, in multiphase flow in minifluidic channels, gravity forces has no effect in capillaries for Bo <3.37. Furthemore, in micro/minichannels, interfacial forces often dominate gravity forces Bo $<1$. As can be seen in Fig. 8, the interfacial tension results in Bond numbers less than 1 only for the fish oil and water and hexane and silver nitrate fluid pairs. For all other systems, the interfacial tension is too low to give a bond number less than 1 at $1 / 16 "$ hydraulic diameter.

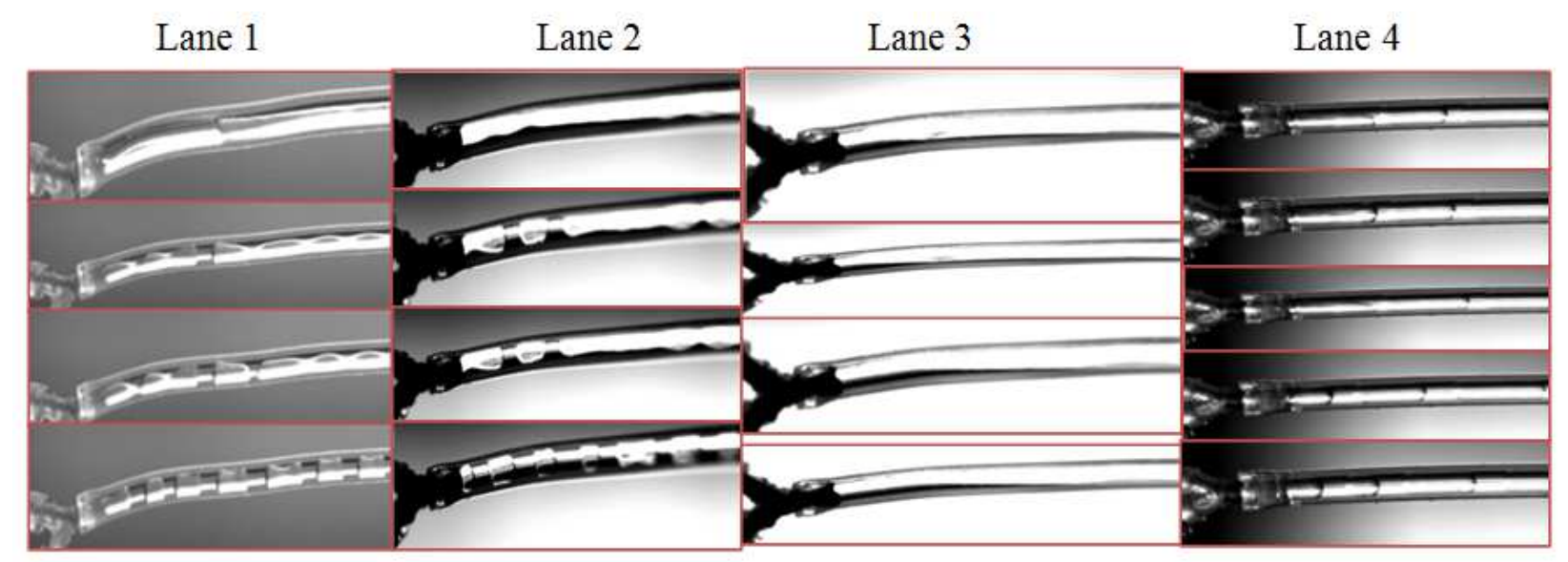

Fig. 5. Destabilization of Stratified flow after pump is stopped. Oil Phase on Bottom in the "Y" Junction and the aqueous phase in top in "Y" Junction and the destabilization of stratified flow that are observed in a 1/16th Inch of internal diameter PFA minichannel. The organic phase enters from bottom at $3.33 \mathrm{ml} / \mathrm{min}$ and aqueous phase enters from top at $10 \mathrm{ml} / \mathrm{min}$; Lane 1 : Fish Oil/Water system (FO on Bottom in Y junction); Lane 2: Fish Oil/Silver Nitrate System; Lane 4: 10\% Hexane 90 FO Silver nitrate system; Lane 4: Hexane/Silver Nitrate System

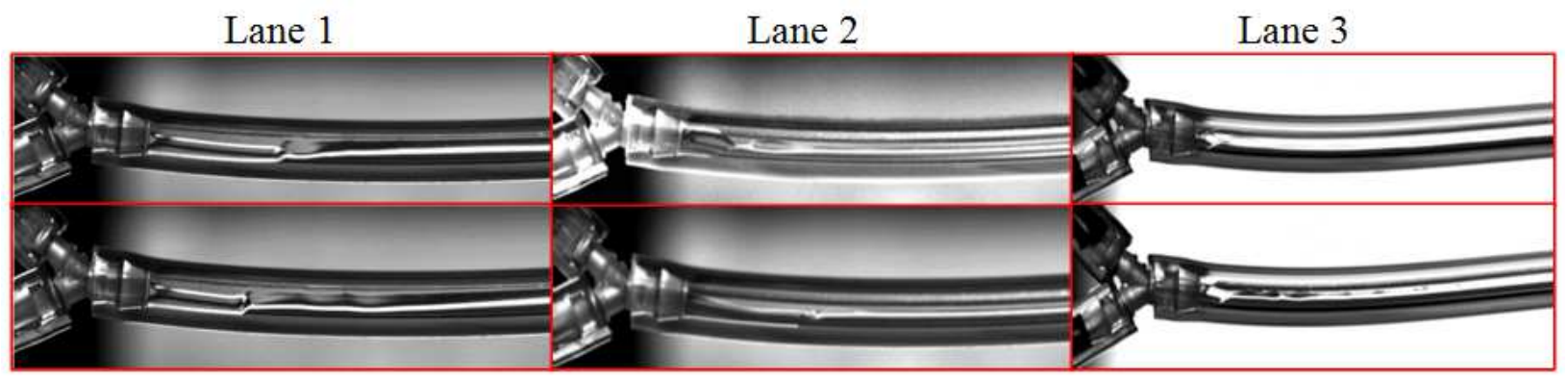

Fig. 6. Phase Inversion Observed in 1/16th inch of Internal Diameter of Tygon channel; Lane 1: Fish Oil water system, Lane 2: Fish Oil Silver Nitrate system, Lane 3: 10\% Hexane 90\% Fish Oil Silver nitrate system 


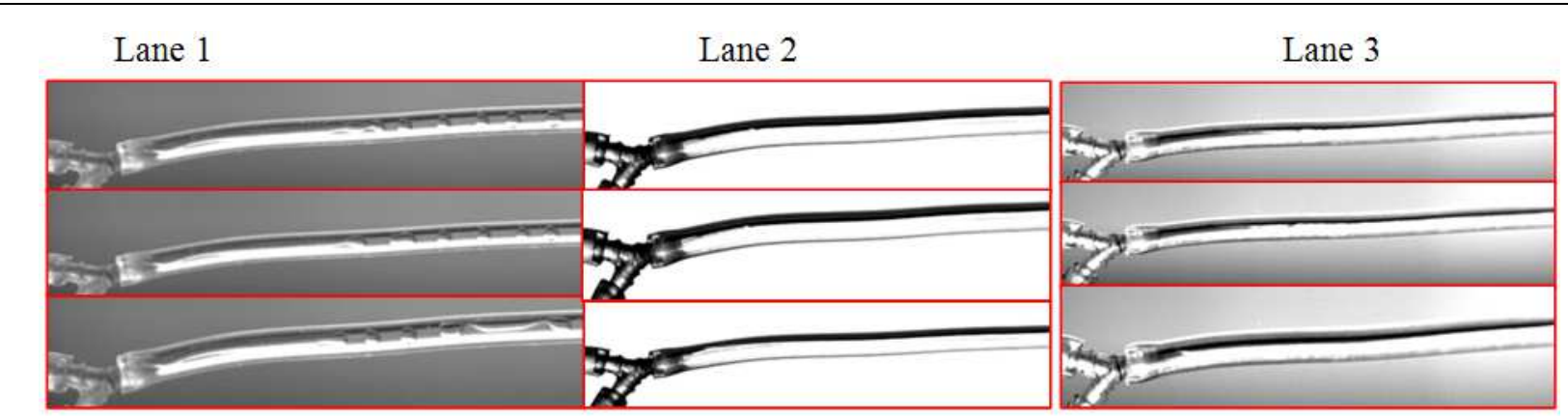

Fig. 7. Phase Inversion Observed in 1/16th inch of Internal Diameter of PFA channel. Lane 1: Fish Oil water system, Lane 2: Fish Oil Silver Nitrate system, Lane 3: 10\% Hexane 90\% Fish Oil Silver nitrate system

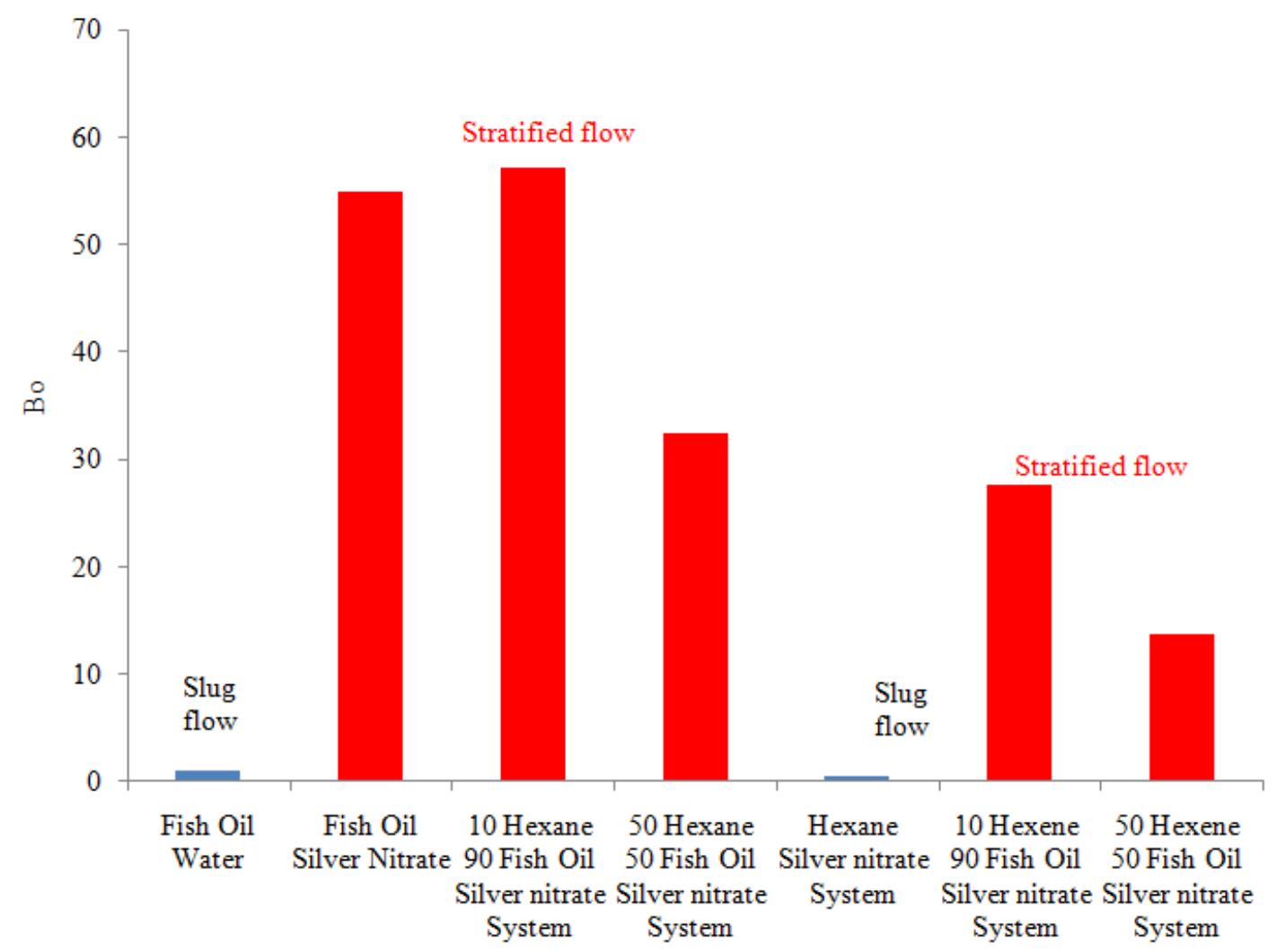

Fig. 8. Bond Number (Bo) are plotted versus the different experimental fluids. The interfacial tension are predicted at $10^{\circ} \mathrm{C}$ using spinning drop tensiometry

\section{Analysis of Flow Patterns Based on Capillary Number and Weber Number}

The plot between $\log (\mathrm{Ca}) \mathrm{Vs} \log (\mathrm{We})$ for fish oil water system, fish oil $\mathrm{AgNO}_{3}$ system, 10 Hex 90 Fish Oil $\mathrm{AgNO}_{3}$ systems, 50\% Hex 50\% Fish Oil $\mathrm{AgNO}_{3}$ system and Hexane $\mathrm{AgNO}_{3}$ system flow in $1 / 16^{\text {th }}$ inch ID of Tygon and PFA mini-channel is shown below Fig. 9. It addresses the competition between various forces between two immiscible fluids and decide the formulation for flow patterns. In this flow pattern map, there are three important region namely:
- Stratified flow region

- Transition flow region

- Slug flow region

Analysis of Flow Pattern Based on Capillary Number and Reynolds Number

So, the observed flow patterns can be explained by a competition between the main forces due to interfacial tension and viscosity. The plot between Log of Capillary Number Vs Reynolds Number for Fish Oil Water System, Fish Oil $\mathrm{AgNO}_{3}$ System, 10 Hex 90 Fish Oil $\mathrm{AgNO}_{3}$ 
System, 50\% Hex 50\% Fish Oil $\mathrm{AgNO}_{3}$ System and Hexane $\mathrm{AgNO}_{3}$ System flow in 1/16th inch ID of Tygon and PFA mini-channel (Fig. 10). Similarly in the flow transition map, it categories into three regions namely:

- Stratified flow region

- Transition region

- Slug flow region

\section{Role of Interfacial Tension in Flow Pattern}

The interfacial tension of the experimental fluids are evaluated using spinning drop tensiometer. The addition of alkanes into the oil phase of the Fish Oil Silver Nitrate binary system is to elevate the interfacial tension between fish oil silver nitrate solution. The mean value of Interfacial tension of the experimental fluids are mentioned in the Fig. 11.

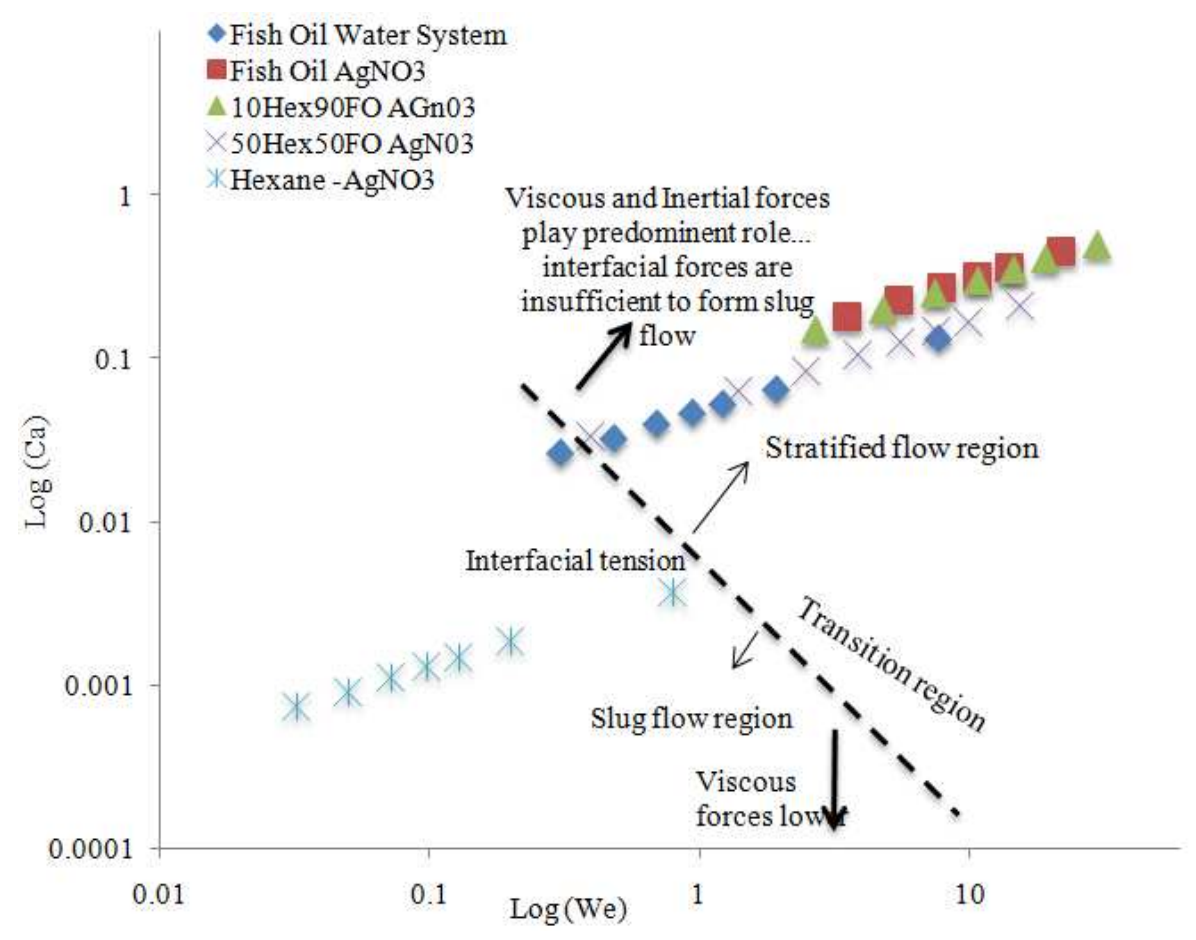

Fig. 9. Log of Capillary number Vs. log of Weber number

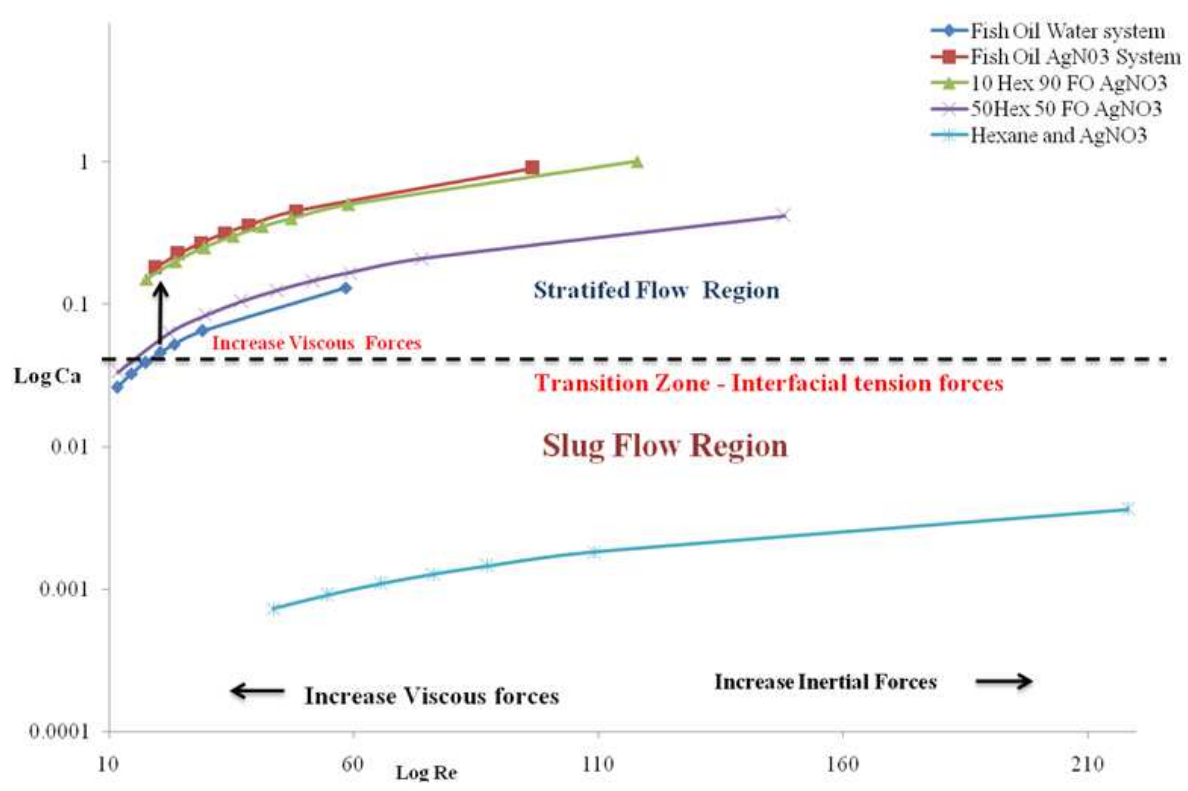

Fig. 10. Log of capillary number Vs Reynolds number 


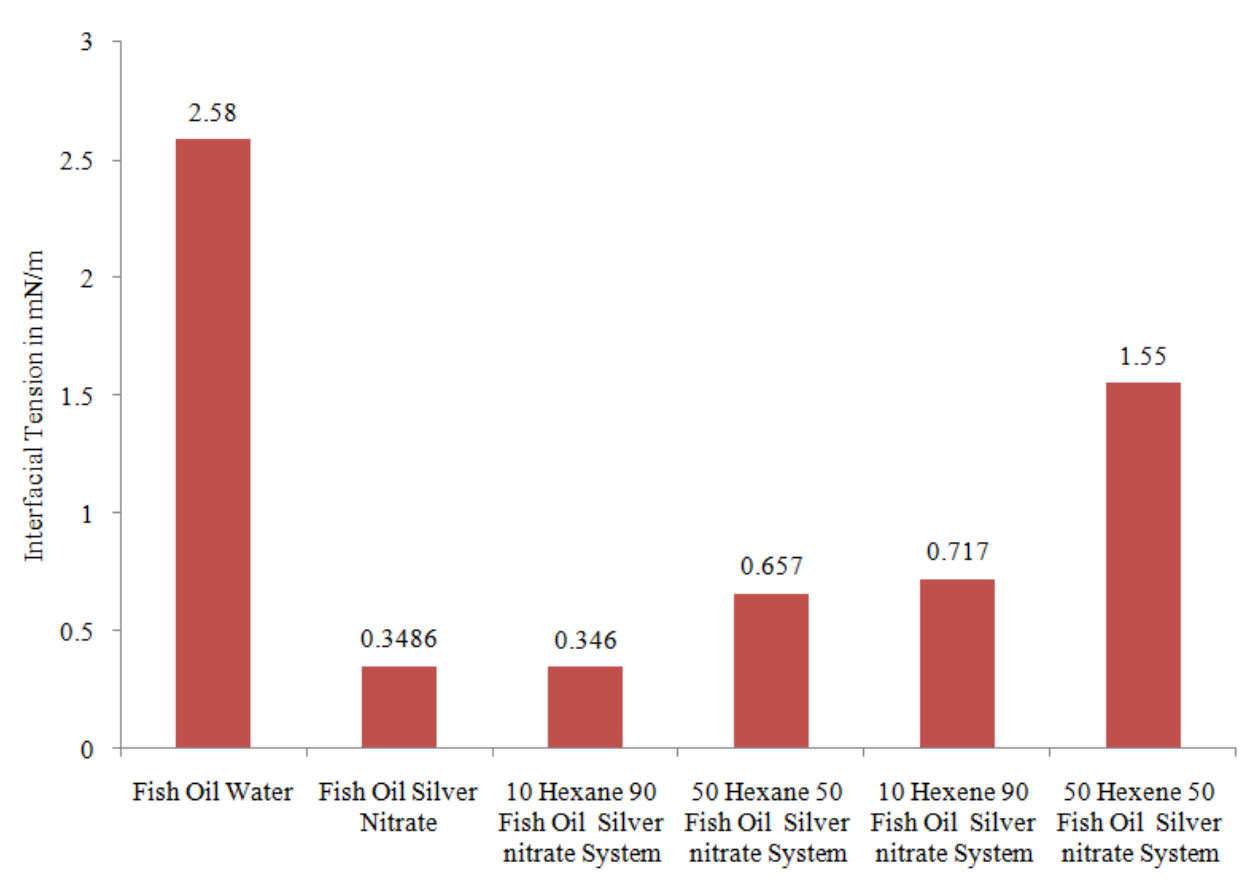

Fig. 11. The values of Interfacial tensions of experimental fluids from spinning drop tensiometer

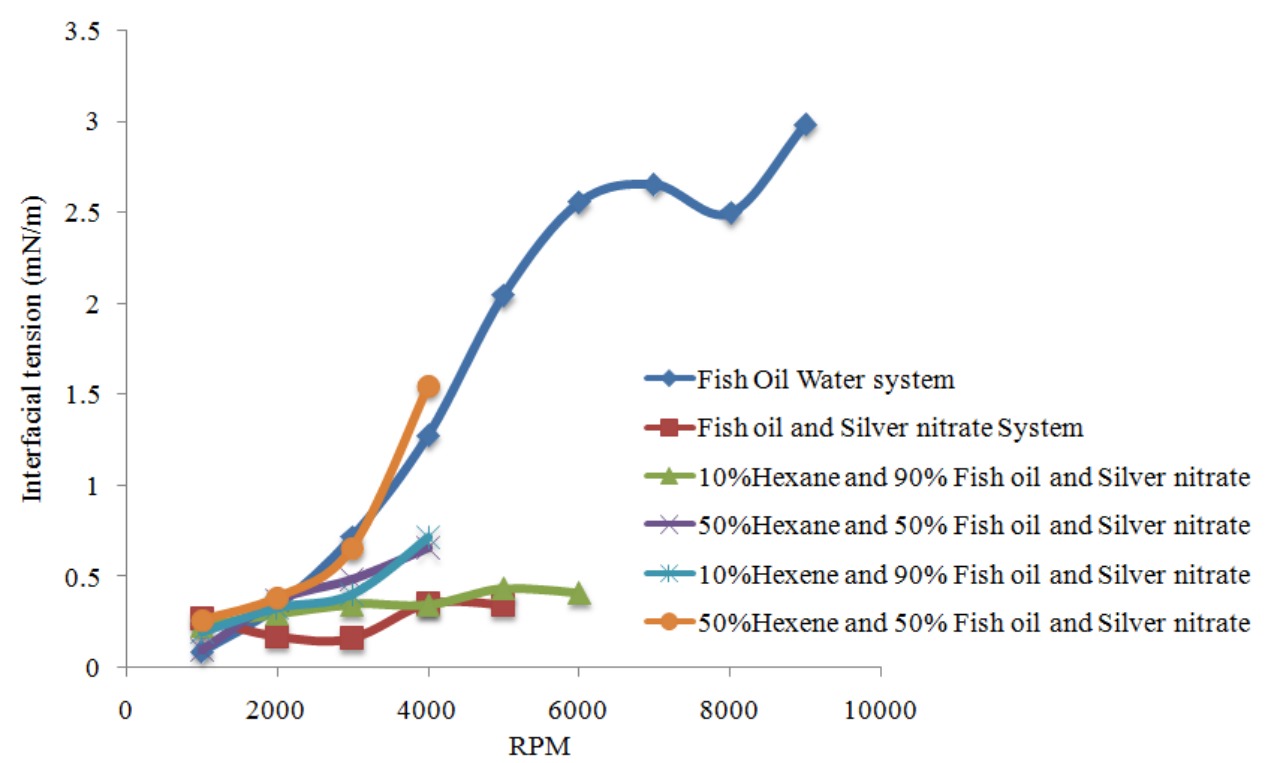

Fig. 12. Interfacial tension studies for experimental fluids by spinning drop tensiometry

The Fig. 12 confirmed that there are some limitations in the measurement of Interfacial tension of experimental fluids due to the physical nature of fish oil and silver nitrate solution. At high angular speeds (Above 4000 RPM), There were unusual behaviour of Fish oil and silver nitrate solutions in the capillary of spinning drop tensiometer such as difficult in elongation of heavy phase in the capillary at high rotational speeds.

\section{Discussion}

The performing extraction process at mini/microscale is a proved process intensification technology and also an alternative for conventional extraction processes (Benz et al., 2001). The previous investigations confirmed that the reactions at mini/microscale enhance the heat and mass transfer including reaction rate by means of effective flow profile at these miniaturized 
dimensions (Dummann et al., 2003). My previous studies confirmed that the mini-fluidic extraction of Omega 3 PUFA from fish oil shows a significant yield of bioactive compounds such as EPA and DHA (Kirubanandan, 2015). Moreover, the flow dynamics and pattern at mini/micro scale is unique from the conventional channels (Chung et al., 2004). In mini/micro scale systems, the surface forces increase until gravitational forces no longer have a significant impact on the hydrodynamics of the system. Interfacial tension forcesbegin to play a more predominant role in determining flow properties due to the reduction of channel diameter (Günther and Jensen, 2006). Therefore, the miniaturization of the systems causes a shift in dominant forces which results inthe flowstabilities. Based on hydraulic diameter size, the channel are classified intoconventional $\left(\mathrm{D}_{\mathrm{h}}>3 \mathrm{~mm}\right)$, Mini-channels $\left(200 \mu \mathrm{m}<\mathrm{D}_{\mathrm{h}}<3 \mathrm{~mm}\right)$ and micro channels $\left(10 \mu \mathrm{m}<\mathrm{D}_{\mathrm{h}}\right.$ $<200 \mu \mathrm{m}$ ) (Burns and Ramshaw, 2001). The most common flow profile for multiphase applications in these systems is slug/Taylor flow or emulsified flow, with stratified flow rarely observed due to the increased dominance of surface forces relative to gravity. These flow patterns have both pros and cons in their application.

Slug flow is characterized by alternating "slugs" of the two immiscible phases which travel through the channel at comparable rates. These slugs typically occupy the entire cross-section of the channel except for a wetted film layer on the wall and are characterized by recirculation within each slug which significantly enhances mass transfer (Taha and Cui, 2004). The flow profile in these reactors approaches that of idealized plug flow reactors, with a number of other benefits in terms of surface area per unit volume (Burns and Ramshaw, 2001). This profile has been observed in previous studies which used an idealized "fish oil" mixture consisting of purified EPA/DHA dissolved in n-heptane solvent. The real fish oil/raw fish oil contained numerous compositions of various fatty acids which reduce the interfacial tension relative to that of idealized solvent mixtures, resulting in a stratified flow within the channels used in this study. Another reason for stratification the flow is the drastic density difference between fish oil ethyl ester and silver nitrate solution. This is extremely odd, as very few fluids form stable stratified flow in millimetre-scale geometries.

In mini scale dimentions, the occurance of different flow patterns is attributed to the competition between interfacial, inertia, gravity and viscous forces among organic phase and aqueous phase. The interfacial force tends to minimize the interfacial energy by decreasing fish oil ethyl ester and aqueous phase interfacial area i.e., formation of droplets and slugs. The inertial force tends to extend the interface in the flow direction and keep the fluid continuous. Also, Due to velocity difference between organic phase and aqueous phase across the interface, the interface could become wavy. In the case of Fish Oil Ethyl Ester-Water system, the water and oil densities difference are close, the diameter of channel is 1.58 $\mathrm{mm}$, the bond number Bo, defined below is small (Bo $<1)$ which indicates the gravitational effects on the flow pattern could be ignored at flow transition. In the range of oil and water flow rate tested in this investigation, flow pattern transitions occurred mainly with the change in the flow rate of $3.5 \mathrm{ml} / \mathrm{min}$ water and oil flow rate of $1 \mathrm{ml} / \mathrm{min}$.

The Most Important Reason for Destabilization of Flow at Mini Scale Might be a Drastic change in density difference between fish oil and water and interfacial tension causes destabilization of stratified flow. Furthermore, oil water interface where the velocity profile at the interface is discontinuous and causes in stability in flow. Once flow is stabilized and constant velocity is reached, coalescence of the oil slugs and droplets giving rise to a continuous film. In these cases, destabilization of stratified flow is caused by a change in the density of the fluid between two phases and decrease in velocity of fish oil and water phase after pump shut off. It is observed that the flow position of oil will not affect the flow pattern. In the case of liquid-liquid extraction of omega 3 PUFA from fish oil ethyl ester with silver nitrate solution in mini-channel contactor, A flow rate of $5 \mathrm{ml} / \mathrm{min}$ for aqueous phase and $1.47 \mathrm{ml} / \mathrm{min}$ for oil phase are fixed and designed for mini-fluidic slug flow reactor according to stoichiometry requirement for reaction between Silver nitrate solution and fish oil EE. Therefore, the stratification of flow in the Tygon and PFA at flow rate of $5 \mathrm{ml} / \mathrm{min}$ is observed. However, stratified flow forms once the flow is stabilized and then once the pump stop. Destabilization of stratified flow occurs and also while in destabilization of flow, sometime wavy annular flow are observed with fish oil water system at this flow rate. Phase inversion of dispersed phase (fish oil ethyl ester) is defined as the transition of a phase from being dispersed to continuous. At high flow rate, phase inversion observed in fish oil/water and fish oil/silver nitrate system (Pielaa et al., 2009). From the physical properties, viscosities of organic and aqueous phases seem to have greatest effect. However, interfacial tension and density differences among two phases, the viscosities of the phases play an important role on the phase inversion point. In two phase flow in mini-channel, a phase inversion phenomenon in Tygon mini-channel has been observed at high flow rate at $10 \mathrm{ml} / \mathrm{min}$. 
Discussing about flow pattern maps, the ratio of inertia force to interfacial force is expressed by Weber number $(\mathrm{We})$ and the ratio between viscous force and interfacial force is expressed by Capillary number. Moreover, the analysis of flow pattern at mixing of aqueous phase and organic phase in Y-junction in mini-channel, the Weber number and capillary number are calculated for mixed phase (aqueous and organic) and the various forces action on the flow patterns are commented.

In fish oil water system and hexane silver nitrate system, the flow transition from stratified flow to Slug flow $(\mathrm{We}<1)$ is observed and at this point, inertial forces are negligible $(\mathrm{We}<1)$ and interfacial tension force dominates the inertial forces and cause onset of slug flow in the mini-channel whereas in the case of Fish Oil $\mathrm{AgNO}_{3}$ System, $10 \mathrm{Hex} 90$ Fish Oil $\mathrm{AgNO}_{3}$ System, 50\% $\mathrm{Hex} 50 \%$ fish $\mathrm{Oil} \mathrm{AgNO}_{3}$ system (We $>1$ ), Inertial forces dominate interfacial tension forces due to the increase of density of silver nitrate solution and cause stratification in flow. Similarly, in the view of capillary number for hexane silver nitrate system, $\mathrm{Ca}<0.002$, Interfacial tension forces dominant the viscous forces which cause the slug flow in mini-channel at flow rate of $5 \mathrm{ml} / \mathrm{min}$.

In order to define quantitatively the influence of the interfacial tension and other inertia and viscous force in flow, the analysis of flow pattern map is based on capillary and Reynolds number of mixed phases has been investigated. Generally, mini-fluidic technology operates at low Reynolds number. In multiphase systems, the Reynolds numbers are low, but the flow can be nonlinear due to interactions at the interface between the immiscible fluids. In order to study flow patterns between fish Oil and water/silver nitrate system, Dimensionless numbers used to explain the competition between interfacial tension and gravity forces between fish oil/water and Fish Oil/silver nitrate system. Therefore, the interfacial tension, viscous force and gravity forces control flow patterns because they depend on the channel diameter (Thorsan et al., 2001).

The capillary number is chosen for flow pattern analysis because the viscous forces and the interfacial tension are the dominating forces in flow pattern in mini-fluidic channel at lower flow rates. The addition of hexane decreases slightly the capillary number in comparison to the fish/water system due to the effect of the interfacial tension for the identical linear velocity. Therefore, the addition of hexane in the organic phase increases the interfacial tension in comparison to viscous forces. However, the stratified flow pattern doesn't change after addition of organic solvent. If the flow of two immiscible fluids is dominated by the interfacial tension, slugs are formed because the interfacial tension reduces the interfacial area (Joanicot and Ajdari, 2005).
The addition of non-polar organic solvent into the organic phase (fish oil) increases the mean capillary number in comparison to the fish oil/silver nitrate system. This means that the viscous forces increase in comparison to interfacial tension. Viscosity produces a resistance to shear (Atenica and Beebe, 2005) and the viscous stresses act to extend and drag the interface downstream (Joanicot and Ajdari, 2005). If the viscous stress is the main forces, stratified flow arises. It is observed that viscosity of fish oil/silver nitrate system is higher than fish oil water system and the addition of organic solvents to the organic phase slightly drops the viscosity however stratified flow is observed.

An increase in the linear velocity leads to an increase in the viscous forces and produces the stratified flow. As can be observed in Fig. 10, the inertia forces tend to produce stratified flow. More precisely, inertia counters parallel movement creating turbulence. For all the experiments reported, the mean Weber numbers are smaller than 1. Therefore, the interfacial tension dominates the inertia forces producing slugs (Zhao et al., 2006). It showed that if inertia forces dominate $(\mathrm{We}>10)$, the turbulence appears and annular flows are observed.

The flow pattern map can be divided into three different zones based namely, surface force dominant, transition and interfacial tension force dominant in flow patterns. To develop a flow pattern map, care must be taken at which axial location flow patterns are observed. It is necessary to explain various dominant forces which affect the flow patterns in mini-channel. Gravity forces Vs interfacial tension is commented.

\section{Interfacial Dominant Flow Pattern}

The low values of capillary and Weber numbers confirm that the interfacial forces dominant in slug flow pattern. Due to interfacial effects, water formed a dispersed phase of slugs in the continuous fish oil stream ethyl esters. The water slugs had a bullet shaped (Fig. 2 and 3 Fish Oil Water System) and were surrounded by the oil film. The viscous forces sheared and deformed the water slugs, preventing them from touching the channel wall. If the viscous forces were negligible, the dispersed phase could fill the entire cross section of the mini-channel. The formation of slugs shows that these flow patterns are controlled by the interfacial tension. However, in the slug flow pattern, the inertia force also plays major role since the slugs are long in the case of fish oil/water system and hexane/silver nitrate system.

\section{Transition Zone where Interfacial Force = Inertial Force Flow Pattern}

In fish oil water system, both slug and wavy annular flow were observed in transition zone. When 
the inertia force controlled the flow pattern, the core flow was continuous. On other hand, when interfacial forces controlled the flow pattern, the core flow become discontinuous and dispersed. In wavy annular flow pattern of fish oil water system, though the water core was continuous, wavy shaped deformation of the oil water interface were seen. The wavy-shaped interfacial deformation was caused by an interfacial tension effect in the reduction of flow rate of water. At transition zone, the low values of capillary number $\mathrm{Ca}<0.0456$ and $\mathrm{We}<0.9338$, indicate that the interfacial tension effects were strong enough to disturb the interface. Furthermore, Interfacial tension force dominant in the limit of $\mathrm{We}<<1$ and dispersed flow were observed in this region. The transition from wavy annular flow and slug flow to stratified flow continuous flow pattern with increase in capillary number is observed. It is observed that an increase in the capillary number would shift the flow pattern from the slug flow pattern to stratified flow region.

\section{Buoyancy Force Dominant Region}

In this region, stratified flow pattern was observed. Appearance of stratified flow indicated that the inertia, viscous and gravity force dominant and overcomes the interfacial tension force by high flow rate. Moreover, the viscous fish oil was more wetting compared to water and silver nitrate solution and formed stable film around the entire inner wall of the mini-channel. Also the oil and water/silver nitrate solution forms a stratified flow pattern because of a drastic density difference between oil phase and aqueous phase and gravity force dominant and overcomes the interfacial tension force due to high density of silver nitrate solution.

In micro/mini-fluidic channel, usually two characteristic flow regimes observed are stratified flow and slug in various liquid-liquid extractions. In the case of fish oil- $\mathrm{AgNO}_{3}, 10 \mathrm{Hex} 90 \mathrm{FO}-\mathrm{AgNO}_{3}, 50 \mathrm{Hex} 50$ $\mathrm{FO}-\mathrm{AgNO}_{3}$, stratified flow were observed and the liquidliquid interface is flat and negligence of surface tension induced curvature and gravity force and inertia force were dominant in the stratified flow region.

Furthermore, the velocity of oil phase and aqueous phase is difference in residence time and fully developed flow and better mass transfer. Donaldson (2013) confirmed that that the shortest residence time of the developed mini-fluidic system with stratified flow was $\sim 36$ seconds, far in excess of the $15 \mathrm{sec}$ required to reach equilibrium in the previous work where slug flow was observed in Kamio et al. $(2010 ; 2011)$. In the aspect of performance of mini-fluidic system with stratified flow pattern, the yield of EPA/DHA was around $75-80 \%$. Though the stratified flow pattern was observed in minifluidic system in fish oil silver nitrate system, such flow pattern has low Reynolds number, small diffusion path and large interfacial area (Vir et al., 2014). The addition of non-polar organic solvent hexane into the fish oil doesn't change the stratified flow pattern into slug flow. In addition to fluids property, the material of the wall plays a critical role in determining flow regime. Food grade Tygon mini-channel is wetted well by Oil Phase.

The data would suggest a significant variation in interfacial tension depending on whether or not silver nitrate is present in the solution and if hexane and hexene are added to the fish oil, the fish oil and distilled water had interfacial tension which was in the upper limit of the instrument's ability to measure, as illustrated by the steady rise in calculated surface tension with RPM (where RPM's above 7000 to 9000 can create some difficulties in the equipment used). In contrast, fish oil in silver nitrate solution was at the lower end of the instrument's capabilities, where the interface would breakup up rapidly at rotation rates before stable surface tension measurements could be obtained. The $10 \%$ by wt., of hexane/hexene addition resulted in an apparent increase in surface tension. About $50 \%$ of hexane/hexene had a significant increase in the interfacial tension, rapidly moving past the instrument's ability to measure accurately. However, the addition of hexane either $10 \%$ or $50 \%$ to fish oil with silver nitrate system does not change the flow pattern in the mini-channel and cause only stratified flow pattern.

These trends are important for future processing considerations, both in recognizing that the low surface tension between fish oil and silver nitrate will facilitate contacting and mass transfer, while possibly making separation difficult. The addition of hexane or, preferably, hexene could use to help in separating the two phases in design of mini-fluidic technology for liquid-liquid extraction of EPA/DHA from fish oil ethyl ester. In SDT, Interfacial tension is function of spinning drop tensiometer. It is noted that the stable value of IFT obtain, as RPM increasing represent the actual interfacial tension.

\section{Conclusion}

Two phase flows in mini-channel have a wide range of applications in chemical and biochemical processing especially liquid-liquid extraction for omega 3 PUFA from fish oil using silver nitrate solution. An experimental study of viscous fish oil ethyl esterwater/silver nitrate solution flow in Tygon and PFA mini-channel with an ID of $1.58 \mathrm{~mm}$ have been performed. Different flow patterns were observed with a constant flow ratio of 3 with the change in flow rate of fish oil and silver nitrate solution. Since the Tygon minichannel and PFA mini-channel were initially saturated with fish oil, the stratified flows were observed. The 
various flow patterns of fish oil ethyl esters and various aqueous phases in two types of mini-channel such as food grade Tygon channel and PFA channel have been investigated. Furthermore, the flow patterns would affect the extraction processes in food grade slug flow minichannel. It is noted that the stratified flow forms in the Tygon channel at the flow rate of $5 \mathrm{ml} / \mathrm{min}$. The flow pattern maps were presented based on Bo, We, Ca and Re. Three different zones were distinguished in flow pattern map namely:

- Interfacial tension force dominant-Slug flow region

- Transition region

- Buoyancy force dominant-Stratified flow region

Furthermore, the addition of organic solvent into the fish oil ethyl ester increase the interfacial tension between fish oil and silver nitrate system, However, There was no transition from stratified flow into slug flow in the fish oil silver nitrate system by addition of hexane into oil phase. In order to design slug flow based mini-fluidics contactor for extraction of EPA/DHA from fish oil ethyl ester using silver nitrate solution, it is important to understand the hydrodynamics of the fish oil silver nitrate system and the addition of organic solvents into the system in the mini-channel. Stratified flow pattern was observed in the designed mini-fluidic system.

\section{Acknowledgement}

Financial Support by DSM Ocean Nutrition is gratefully acknowledged. Author is grateful to Dr. Adam A. Donaldson for providing funds for his graduate studies MASc in Chemical Engineering at Dalhousie University, Halifax, NS, Canada.

\section{Ethics}

The part of this manuscript are submitted as a conference paper at the ISME 2015 at Indian Institute of Technology, Delhi, India. It was one of the chapter in my master thesis which is submitted to Faculty of Graduate Studies, Dalhousie University, Halifax, Nova Scotia, Canada. Furthermore, the results would be considered for comparison with Computational Fluid Dynamics (CFD) modeling and simulation in future and will be presented in a conference paper or a journal article with proper citation.

\section{Reference}

ASTM D1480-12, 2012. Standard test method for density and relative density (specific gravity) of Viscous Materials by Bingham Pycnometer. ASTM International, West Conshohocken, PA.
Atenica, J. and D.J. Beebe, 2005. Controlled microfluidic interfaces. Nature, 437: 648-655. DOI: $10.1038 /$ nature 04163

Benz, K., K.P. Jäckel, K.J. Regenauer, J. Schiewe and K. Drese et al., 2001. Utilization of micromixers for extraction processes. Chem. Eng. Technol., 24: 11-17. DOI: $\quad 10.1002 / 1521-4125(200101) 24: 1<11:: A I D-$ CEAT11>3.0.CO;2-Q

Breivik, H., F.O. Libnau and O. Thorstad, 2012. Process for concentrating omega-3 fatty acids. Patent -US WO 2012038833 A1.

Burns, J.R. and C. Ramshaw, 2001. The intensification of rapid reactions in multiphase systems using slug flow in capillaries. Lab Chip, 1: 10-15. DOI: 10.1039/B102818A

Chung, P.M.Y., M. Kawaji, A. Kawahara and Y. Shibata, 2004. Two-phase flow through square and circular microchannels-effects of channel geometry. J. Fluids Eng., 126: 546-552. DOI: $10.1115 / 1.1777227$

Donaldson, A., 2013. Silver-based liquid/liquid extraction of EPA/DHA from fish oil ethyl esters: Feasibility analysis of mini-fluidic technology-technical report. DSM Nutritional Products, Halifax, NS.

Dummann, G., U. Quittmann, L. Groschel, W. Agar David and O. Worz et al., 2003. The capillarymicroreactor: A new reactor concept for the intensification of heat and mass transfer in liquidliquid reactions. Catal. Today, 79-80: 433-439. DOI: 10.1016/S0920-5861(03)00056-7

Günther, A. and K.F. Jensen, 2006. Multiphase microfluidics: From characteristics to chemical and materials synthesis. Lab Chip, 6: 1487-1503.

Joanicot, M. and A. Ajdari, 2005. Droplet control for microfluidics. Science, 309: 887-888. DOI: $10.1126 /$ science. 1112615

Kamio, E., Y. Seike, H. Yoshizawa and T. Ono, 2010. Modeling of extraction behavior of docosahexaenoic acid ethyl ester by utilizing slug flow prepared by microreactor. AICHE, 56: 2163-2172. DOI: 10.1002/aic.12132

Kamio, E., Y. Seike, H. Yoshizawa, H. Matsuyama and T. Ono, 2011. Microfluidic extraction of docosahexaenoic acid ethyl ester: Comparison between slug flow and emulsion. Ind. Eng. Chem. Res., 50: 6915-6924. DOI: 10.1021/ie102207c

Kirubanandan, S., 2015. Mini-fluidic silver based solvent extraction of EPA/DHA from fish oil. MSc Thesis, Dalhousie University, Halifax, Canada.

Pielaa, K., R. Delfos, G. Ooms, J. Westerweel and R.V.A. Oliemans, 2009. Phase inversion in the mixing zone between a water flow and an oil flow through a pipe. Int. J. Multiphase Flow, 35: 91-95. DOI: 10.1016/j.ijmultiphaseflow.2008.08.002 
Seike, Y., E. Kamio, T. Ono and H. Yoshizawa, 2007. Extraction of ethyl ester of polyunsaturated fatty acids by utilizing slug flow prepared by microreactor. J. Chem. Eng. Japan, 40: 1076-1084. DOI: $10.1252 /$ jcej.07WE144

Shanmugam, K. and A.A. Donaldson, 2015. Extraction of EPA/DHA from 18/12EE Fish Oil using $\mathrm{AgNO}_{3}(\mathrm{aq})$ : Composition, yield and effects of solvent addition on interfacial tension and flow pattern in mini-fluidic systems. Indus. Eng. Chem. Res., 54: 8295-8301. DOI: $10.1021 /$ acs.iecr.5b01780

Taha, T. and Z.F. Cui, 2004. Hydrodynamics of slug flow inside capillaries. Chem. Eng. Sci., 59: 1181-1190. DOI: $10.1016 /$ j.ces.2003.10.025
Thorsan, T., R.W. Roberts, F.H. Arnold and S.R. Quake, 2001. Dynamic pattern formation in a vesiclegenerating microfluidic device. Phys. Rev. Lett., 86: 4163-4166. DOI: 10.1103/PhysRevLett.86.4163

Vir, A.B., A.S. Fabiyan, J.R. Picardo and S. Pushpavanam, 2014. Performance comparison of liquid-liquid extraction in parallel microflow. Ind. Eng. Chem. Res., 53: 8171-8181.

DOI: $10.1021 /$ ie4041803

Zhao, Y., G. Chen and Q. Yuan, 2006. Liquid-liquid two-phase flow patterns in a rectangular microchannel. AIChE J., 52: 4052-4060.

DOI: 10.1002/aic.11029 